\title{
Prevalence and Outcome of Cesarean Section at Gandaki Medical College Teaching Hospital and Research Centre, Pokhara, Nepal
}

\author{
Gurung $R T^{\prime *}$, Gurung $\mathrm{G}^{2}$, Shrestha $\mathrm{R}^{\prime}$, Gurung $\mathrm{T}^{1}$, Sharma $\mathrm{P}^{3}$ \\ 'Lecturer, Department of Obstetrics \& Gynecology, ${ }^{2}$ Lecturer, Department of Ophthalmology, ${ }^{3}$ Lecturer, Department of Radiology \\ Gandaki Medical College \& Teaching Hospital, Pokhara, Nepal
}

\section{Keywords \\ Cesarean section, Mother, Newborn \\ Corresponding author \\ *Dr Rubina Tamrakar Gurung \\ Lecturer, Department of Obstetrics \& \\ Gynecology \\ Gandaki Medical College \& Teaching \\ Hospital, Pokhara, Nepal \\ Email: tamrakarrubina@yahoo.com.hk}

\begin{abstract}
Introduction: Gandaki Medical College Teaching Hospital is providing specialized obstetrician and gynecologist services since last one decade.

Objectives: This study was conducted to know the prevalence and outcome of cesarean section at Gandaki Medical College Teaching Hospital and Research Centre during 2013 - 2015 A.D. (2070 - 2072 B.S.).
\end{abstract}

Methods: It was a retrospective study of women undergoing cesarean section from 2013 to 2015 A.D. (2070 - 2072 B.S.).

Results: During the period of three years 2013 - 2015 A.D. (2070 2072 B.S.) total deliveries were 2627. Among total deliveries cesarean section was performed in 1084 patients (41.26\%). In 1084 patients $803(74 \%)$ cesarean sections were performed as an emergency and 281 (26\%) were elective. In this study 15 to more than 35 years old patients were enrolled. Among cesarean sections done, 52\% were primigravida, $46 \%$ were para and $2 \%$ were grandmulti. The indications for cesarean section were CPD (28\%), fetal distress (25\%), previous cesarean (14\%), malpresentation (7\%), premature rupture of membrane $(5 \%)$, pre-eclampsia (6\%), failed induction (5\%), bad obstetric history (2\%), antepartum hemorrhage (1\%), and twins (1\%).

Conclusion: This study at Gandaki Medical College Teaching Hospital and Research Centre provided the prevalence, outcome and different indications of cesarean section which is life saving for both mother and newborn. And also the study can be useful to the hospital to improve facilities for safe motherhood and safety of newborn.

\section{INTRODUCTION}

Cesarean delivery defines the birth of a fetus via laparotomy and then hysterotomy. The origin of cesarean is uncertain and was reviewed in the $23^{\text {rd }}$ edition of Williams Obstetrics (Cunningham, 2010). There are two general types of cesarean delivery-primary refers to a first-time hysterotomy and secondary denotes a uterus with one or more prior hysterotomy incisions. Neither definition includes removal of the fetus from the abdominal cavity in the case of uterine rupture or with abdominal pregnancy ${ }^{1}$. The first modern cesarean section 
was performed by German gynecologist Ferdinand Adolf Kehrer in $1881^{2}$. The indications for cesarean section have been varying tremendously through its documented history, and they have been shaped by religious, cultural, economic, professional and technological developments. Cesarean section has been part of human culture since ancient times, but the early history of cesarean section remains unclear. It is commonly believed to be derived from the surgical birth of Julius Caesar, but this seems unlikely, since his mother Aurelia is reputed to have lived to hear of her son's invasion of Britain ${ }^{3}$.

At that time the procedure was performed only when the mother was dead or dying, in an attempt to save the child. Cesarean sections were also made because of religious beliefs, so that the baby could be buried separately from the mother. The operation was not intended to preserve the life of the mother. It was not until the $19^{\text {th }}$ century that saving the mother really was a possibility ${ }^{3}$.

Today, a cesarean section is usually performed when a vaginal delivery would put the baby's or mother's life or health at risk, although in recent times it has also been performed upon request for childbirths that could otherwise have been natural. In later years the rate has risen to a record level of $46 \%$ in China, and to levels of $25 \%$ and above in many Asian, European and Latin American countries. In 2009 , the cesarean section rate was $34 \%$ in the United States ${ }^{4}$.

Like other parts of South Asia, Nepal demonstrates a distinct social stratification based on caste system and encompasses a wider socio-economic heterogeneity. There are about 36 castes of people residing in the hilly regions of Nepal. They have been categorized into broader groups giving five classes that include upper caste group, relatively advantaged janajatis, disadvantaged janajatis, dalits and religious minorities. The dogma of the caste system though, still remains a contentious issue; it continues to act as an obstacle in the development of communities belonging to the lower social class. Main drawback of this caste system is that lower people often face a multitude of disadvantages in socio-economic marginalization, participation in decisionmaking processes and employment opportunities. This ultimately affects the health issues among different groups. Cesarean section has become a common surgical procedure these days. But due to the lack of education or awareness and poverty among the dalits and disadvantaged janajatis, they have not been able to access the hospital for cesarean delivery. There has been a great difference seen among the different caste groups who undergo cesarean section.

Therefore, the objective of the study was to determine the prevalence of cesarean section among different castes in Western Nepal ${ }^{5}$.

This study was conducted to know the prevalence and indication of cesarean Section at Gandaki Medical College Teaching Hospital. The study can also support the district health care program to educate and motivate people for routine antenatal check-ups in the hospital for the safety of mother and the baby.

\section{METHODS}

The study was conducted at Gandaki Medical College Teaching Hospital and Research Centre. This hospital is a tertiary 645 bedded health care centre. The service has been operative since 2007 A.D. The obstetrics and gynecology department has regular 10 - 15 internists. All the pregnant women in labor and for elective cesarean section were admitted in the maternity ward. They were attended for examination, evaluation and management by internist, medical officer and consultant/lecturer. All the patients for normal deliveries were transferred to the delivery room which has two beds. The patients with indications for cesarean section (Emergency/ elective) were transferred to the pre-operative room. The pre-operative room had six beds where the patients undergo preparation for operation. The Anesthesiologists (five to six) have done pre-anesthetic check prior to the procedure.

Opening the abdomen can be performed with either a pfannenstiel or a vertical skin incision, but pfannenstiel is the preferred. A pfannenstiel incision is associated with less postoperative pain, greater wound strength, and better cosmetic results than the vertical midline incision.

For the lower segment cesarean section (LSCS), a pfannenstiel rather than a vertical incision is recommended for most women. This is associated with less blood loss, less need for bladder dissection, is easier to reapproximate, and has a lower risk of rupture in subsequent pregnancies. A spontaneous, rather than a manual extraction of the placenta is recommended. If the woman has subcutaneous tissue depth $>/=2 \mathrm{~cm}$, the subcutaneous tissue layer should be closed with sutures.

The concern about the increasing rate of cesarean delivery globally, is due not only to the fact that a cesarean section is expenditure for the society, but it also infers several postoperative issues for the mother. As with all types of surgery, there will always be possible complications during, and after the surgery, and a cesarean section is no exception. 
In the immediate postoperative period, the woman was monitored for evidence of uterine atony, excessive vaginal or incisional bleeding, and oliguria. The blood pressure was also monitored to assess for hypotension or hypertension, which could be signs of intra abdominal bleeding or preeclampsia respectively. The mother may need some instruction on how to hold her newborn to avoid contact with the incision. Early ambulation is encouraged; the mother can take sips of water within eight hours of surgery. The usual drugs and procedures associated with cesarean birth are not a contraindication to breastfeeding.

The major non-anesthesia-related complications related to cesarean delivery are hemorrhage, infection, injury to pelvic organs, and thromboembolic disorders. There are no randomized trials comparing the outcomes of planned vaginal versus planned cesarean delivery for the term cephalic gestation. Moderate quality evidence shows that planned cesarean delivery is associated with less maternal hemorrhage, longer maternal hospital stay, and greater mild neonatal respiratory morbidity than planned vaginal delivery. The risks of severe maternal morbidity are generally higher in women with an unplanned cesarean delivery during labor. Cesarean delivery in the second stage of labor is associated with a slightly higher maternal composite morbidity than in the first stage of labor; however, neonatal morbidity rates are similar for first and second stage cesareans. In a Norwegian study $21.4 \%$ of the women had more than one complication from cesarean section. The complication rates were higher for the operations performed at $9-10 \mathrm{~cm}$ cervical dilatation. General anesthesia, low gestational age, and fetal macrosomia were also identified as independent risk factors for complications ${ }^{6}$. Statistical analysis was done using SPSS software 11.7 version.

\section{RESULTS}

During the period of three years 2013 - 2015 A.D. (2070 - 2072 B.S.) total deliveries were 2627. Among 2627 total deliveries cesarean section was performed in 1084 patients (41.26\%). Emergency cesarean sections were $803(74 \%)$ and $281(26 \%)$ were performed as an elective. In this study 15 to more than 35 years old patients were enrolled. Of total 1084 patients underwent cesarean section $10 \%$ (111) patients were between 15 - 19 years age, $86 \%$ (937) were within 20 - 34 years of age and $4 \%$ were above 35 years old. Among 1084 patients underwent cesarean section, $52 \%$ (568) patients were primigravida,
$46 \%$ (495) patients were para and 2\% (21) patients were grandmulti.

Table 1: Distribution of cesarean section cases by age and parity

\begin{tabular}{lcc}
\hline Variables & No of cesarean sections & Percentage \\
\hline Age (Years) & & \\
$15-19$ & 111 & $10 \%$ \\
$20-34$ & 937 & $86 \%$ \\
$\geq 35 \quad$ Total & 36 & $4 \%$ \\
$\quad$ Parity & 1084 & $100 \%$ \\
Primigravida & 568 & $52 \%$ \\
Para (1 - 4) & 495 & $46 \%$ \\
Grandmulti & 21 & $2 \%$ \\
$\quad$ Total & $\mathbf{1 0 8 4}$ & $\mathbf{1 0 0} \%$ \\
\hline
\end{tabular}

Elective cesarean sections were performed in 281 (26\%) and emergency cesarean sections were done in $74 \%$ (803) patients.

Table 2: Types of cesarean sections, anesthesia, gestational age in weeks at Gandaki Medical College Teaching Hospital during 2013 - 2015 A.D. (2070 - 2072 B.S.)

\begin{tabular}{lcc}
\hline \multicolumn{1}{c}{ Variables } & $\begin{array}{c}\text { No of cesarean } \\
\text { sections }\end{array}$ & Percentage \\
\hline Type of cesarean sections & & \\
Elective & 281 & $26 \%$ \\
Emergency & 803 & $74 \%$ \\
Total & $\mathbf{1 0 8 4}$ & $\mathbf{1 0 0 \%}$ \\
Primary & 930 & $86 \%$ \\
Repeat & 154 & $14 \%$ \\
Total & $\mathbf{1 0 8 4}$ & $\mathbf{1 0 0 \%}$ \\
Bilateral tubal ligation & & \\
Yes & 116 & $11 \%$ \\
No & 968 & $89 \%$ \\
Total & $\mathbf{1 0 8 4}$ & $\mathbf{1 0 0 \%}$ \\
Type of Anesthesia & & \\
General anesthesia & 15 & $1 \%$ \\
Spinal anesthesia & 1069 & $99 \%$ \\
Total & $\mathbf{1 0 8 4}$ & $\mathbf{1 0 0 \%}$ \\
Gestational age in weeks & & \\
$<37$ & 40 & $4 \%$ \\
37 - 42 & 1012 & $93 \%$ \\
$\geq 42$ & 32 & $3 \%$ \\
Total & $\mathbf{1 0 8 4}$ & $\mathbf{1 0 0 \%}$ \\
\hline
\end{tabular}


Fig 1: Indication of cesarean section at Gandaki Medical College Teaching Hospital during the study period

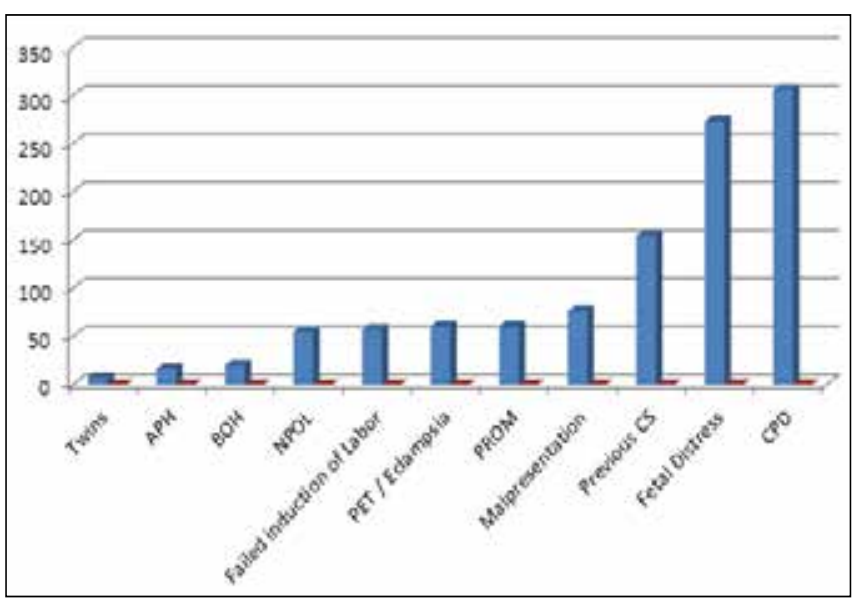

Among 1084 cesarean sections performed at Gandaki Medical College Teaching Hospital and Research Centre, 28\% (306 patients) had CPD, 25\% (273 patients ) fetal distress, $14 \%$ (154 patients) previous cesarean, 7\% (76 patients) malpresentation, 6\% (60 patients) had premature rupture of membrane, $6 \%$ (60 patients) preeclampsia, 5\% (57 patients) failed induction, 5\% (55 patients) presented with non progress of labor, $2 \%$ (20 patients) bad obstetric history, 1\% antepartum hemorrhage and twins.

\section{DISCUSSION}

In this study done at Gandaki Medical College Teaching Hospital and Research Centre among the cesarean sections performed on 1084 patients, elective cesarean sections were done in 281 (26\%) and emergency cesarean sections were in 803 (74\%) patients. The reason for the higher number of emergency cesarean sections performed than elective cesarean might be the number of patients attending the hospital. Majority attending the hospital were from the rural hilly regions of Nepal where the awareness of antenatal check up during pregnancy is either unreachable or the facilities are limited. Most of the elective cesarean sections performed were either local patients of the pokhara valley or those who had proper antenatal check up and motivation. These results were similar to the study done by Raj kumar Thapa, Bishrawa Bhandari et al on prevalence of cesarean sections among different castes in Western Nepal, which stated that low socioeconomic status and long physical distance of more than hours to the hospital acted as a barrier ${ }^{5}$.

Cephalopelvic disproportion was the most common indication for cesarean section in this study done at
Gandaki Medical College Teaching Hospital and Research Centre. Among 1084 (41.26\%) patients, cephalopelvic disproportion was the reason in 306 (28\%) patients. These results were similar to study done by Tadesse E, Adane M, Abiyou M (1996) on cesarean section deliveries at Tikur Anbessa Teaching Hospital, Ethiopia ${ }^{7}$ and Souza JP et al (2010) cesarean section term maternal outcomes ${ }^{8}$.

Nutrition is directly proportional to the pelvic size and shape. The pelvic contraction and stunting growth result from malnutrition. Malnutrition is still major risk factor and responsible for cephalopelvic disproportion in Nepal and other developing countries. These results were similar to study done by Geidam et al (2010) in Nigeria9.

Fetal distress was seen in 25\% (273) of the patients. The results were due to increased use of cardio-tocogram. Similar to the results mentioned by Chhetri $\mathrm{S}$ et al in cesarean section: Its rate and indication in Eastern $\mathrm{Nepal}^{10}$. The study also mentioned the difference in fetal distress in 2006 (8.1\%) and 2007 (10.7\%) in the same institution. Cardio-tocogram is used to monitor the fetal heart rate variability, which if not reassuring, would warrant a cesarean section. Fetal distress is more common indication in developed countries than ours. Unavailability of continuous electronic fetal monitoring in the institution might be the reason.

The maternal indication of cesarean section was previous cesarean section among 154 patients (14\%). The risk of complications rise with increasing number of cesarean deliveries, especially the risk of placenta accrete. Although previous cesarean is not a condition that qualifies for repeat cesarean section, it is normal practice to do it again. Previous cesarean sections increase the risk of placenta previa and uterine rupture ${ }^{11}$. These results were similar to the study done by Kathryn Chu, Hilde Cortier et al on cesarean section rates and indication in Sub Saharan Africa ${ }^{12}$.

Malpresentation is one of the fetal indication; for cesarean section seen among 76 patients (7\%). Breech presentation is one of the types of malpresentation. The incidence of breech presentation decreases with increased gestational age, the prevalence of babies in breech position is $3-4 \%$ at term ${ }^{13}$. Early in the pregnancy many babies are breech, but most turn before birth. If the baby has not turned, it is possible to try an external cephalic version ${ }^{14}$. Some studies show fewer complications for the baby with planned cesarean ${ }^{15}$.

Transverse lie is present in about two out of 1000 births. The fetus can be in complete or partly transverse lie. This 
condition is more usual in multiparous women and in multiple baby pregnancies ${ }^{16}$. The condition usually passes as the birth start with the baby turning its head down due to contractions.

Compound presentation is defined as presentation of a fetal extremity alongside the presenting part. It occurs in one to 700 to one to 1000 of deliveries. It is more common when the pelvis is not fully occupied by the fetus because of low birth weight, multiple gestation, polyhydramnios, or if there is a large pelvis. If the compound presentation does not resolve spontaneously one should do cesarean section $^{17}$.

Prolonged labor is when the duration of the labor exceeds 24 hours. This may be due to a prolonged latent phase, more than 20 hours in a primigravida or more than 14 hours in a multipara, or due to delayed or lacking cervical dilatation in the active phase of labor and protracted descent of the fetus ${ }^{18}$.

In a prolonged labor, fetal distress can occur and the baby needs to be monitored. If there is any indication that the baby is suffering one should proceed with forceps, vacuum or emergency cesarean section depending on the situation ${ }^{16}$.

In this study 5\% (55 patients) presented with nonprogress of labor which was almost similar to the study done by Chhetri et a ${ }^{10}$ where the study showed $8.1 \%$ with prolonged labor.

This study stated $6 \%$ (60 patients) with preeclampsia. Preeclampsia is defined as hypertension after 20th gestational week $^{19}$. The disease affects 2 - 3\% of all pregnant women, it can develop quite rapid and be life threatening for both mother and fetus. The disease leads to two syndromes, one in the mother and one in the fetus. The maternal disease consists of high blood pressure, proteinuria, possible edema and activation of the coagulation system. The maternal disease can further develop into HELLP syndrome (Hemolysis, Elevated Liver Enzymes, Low Platelets) which is a rare, but very dangerous disease. The woman usually has pain in the epigastrium or underneath the right costal arch. She might be nauseous. Suspicion of HELLP syndrome is an emergency. This condition is a threat to the mother's life and therefore emergency cesarean section should be done immediately ${ }^{19}$. The fetal syndrome starts with failing placental function. Pregnancy induced hypertension is hypertension after 20 weeks of gestation without proteinuria, that regress within 12 weeks postpartum ${ }^{19}$.

In placenta praevia the placenta is situated partly over the exit for the fetus. This can lead to a severe bleeding with an extensive blood loss for both mother and child. The typical symptom of placenta praevia is a sudden bleeding without pain or contractions. The bleeding increases as the pregnancy moves forward and pregnant women with this condition is advised to stay close to the hospital. With complete placenta praevia the placenta is covering the whole exit. In this condition cesarean is absolutely necessary and usually takes place in week 37 - 38. In partly placenta praevia birth is possible ${ }^{20}$. Abruptio placenta can present in a traumatic way with severe pain, contractions, blood loss and a bad general condition or it can be without symptoms. The condition is an indication for immediate cesarean section ${ }^{21}$. Antepartum hemorrhage was seen in $1 \%$ of patients. Antepartum hemorrhage which includes placenta previa and abruption placenta is associated with early neonatal and maternal demise ${ }^{12}$. Premature rupture of membrane was seen in $6 \%$ (60 patients), failed induction in 5\% (57 patients), bad obstetric history in 2\% (20 patients). Patients came as an elective cesarean section with twins or multiple babies were $1 \%$. If not everything is in place for an uncomplicated vaginal birth cesarean is recommended when there is more than one baby ${ }^{16}$.

\section{CONCLUSIONS}

This study of three years duration at Gandaki Medical College Teaching Hospital and Research Centre provided the prevalence, outcome and different indications of cesarean section. Cesarean sections performed for appropriate medical or obstetric indications are life saving for both the mother as well as the new born. But the high prevalence of cesarean section is not associated with improved perinatal outcome and it has risks for the mother and the neonate. Therefore to reduce the high prevalence of cesarean sections, each case should be thoroughly evaluated to determine the possibility for vaginal delivery. And also the study can be useful to the hospital to improve facilities for safe motherhood and safety of newborn. 


\section{REFERENCES}

1. Cunningham FG, Leveno KJ, Bloom SL, Spong CY, Dashe JS et al. Williams Obstetrics. $24^{\text {th }}$ edition, chapter 20, page 587.

2. Caesarean section. Wikipedia. Available from http:// en.wikipedia.org/wiki/ Caesarean_section.

3. Cesarean section - a brief history. 1993. Available from http://www.neonatology. org/pdf/cesarean. pdf. Page 5.

4. Boruff $\mathrm{K}$. Health grades reveals $\mathrm{c}$-section rates across America. 2012. Available from: http://www. healthgrades.com/ratings-and-awards/nationalmaternity-care.

5. Thapa RK, Bhandari B, Adhikari K, Katila P, Baral P et al. Prevalence of caesarian section among different castes in Western Nepal. JHAS. 2012; 2(1): 18-21.

6. Hager RME, Daltveit AK, Hofoss D, Nilsen ST, Kolaas T, Øian P, Henriksen T. Complications of cesarean deliveries: Rates and risk factors. American Journal of Obstetrics and Gynecology. 2004; 190: 428e34.

7. Tadesse E, Adane M, Abiyou M. Caesarean section deliveries at Tikur Anbessa Teaching Hospital, Ethiopia. East Afr Med J. 1996; 73: 619-622.

8. Souza JP, Gülmezoglu A, Lumbiganon P, Laopaiboon M, Carroli G et al. Caesarean section without medical indications is associated with an increased risk of adverse short-term maternal outcomes: The 20042008 WHO Global Survey on Maternal and Perinatal Health. BMC Med. 2010; 8: 71.

9. Geidam AD, Audu BM, Kawuwa BM, Obed JY. Rising trend and indications of caesarean section at the University of Maiduguri Teaching Hospital, Nigeria. Ann Afr Med. 2009; 8: 127-132.

10. Chhetri S, Singh U. Caesarian section: Its rates and indications at a tertiary referral center in Eastern Nepal. Nepal Journal Online. http://dx.doi. org/10.3126/hren.v9i3.5587.

11. Silver RM. Landon MB. Rouse DJ. Leveno KJ. Spong CY, Thom EA et al. Maternal morbidity associated with multiple repeat cesarean deliveries. Obstetrics \&
Gynecology. 2006; 107(6): 1226.

12. Chu K, Cortier H, Maldonado F, Mashant T, Ford N et al. Cesarean section rates and indications in SubSaharan Africa: A multi-country study. Medecins sans Frontiers. Sept 2012; 7 (9): e44484.

13. Hickok DE, Gordon DC, Milberg JA, Williams MA, Daling JR. The frequency of breech presentation by gestational age at birth: A large population based study. American Journal of Obstetrics and Gynecology. 1992 Mar; 166(3): 851-2.

14. Hofmeyr GJ, Kulier R. External cephalic version for breech presentation at term. Cochrane Database Syst Rev. 2012; 10: CD000083.

15. Cheong Leung,W. Chung Pun, T. Term breech trial. Lancet. 2001; 357(9251): 225.

16. Henriksen T, Molne K. Chapter 19 Avvikende fødsler, komplikasjoner og intervensjoner. In Bergsjø, P. Maltau, JM. Molne, K. Nesheim, BI. Obstetrikk og Gynekologi. Gyldendal norske forlag. Second edition, 2010.

17. Goplerud J, Eastman NJ. Compound presentation; A survey of 65 cases. Obstet Gynecol. 1953; 1(1): 59.

18. Prolonged labor. The free dictionary by farlex. Downloaded 25.02.2013. Available from: http:// medical-dictionary.thefreedictionary.com prolonged+labor.

19. Maltau JM, Øian P. Chapter 15 Sykdom hos mor i svangerskapet. In Bergsjø P, Maltau JM, Molne K, Nesheim BI, Obstetrikk og Gynekologi. Gyldendal norske forlag. Second edition, first circulation, 2010.

20. Maltau JM. Chapter 16. Blødning i siste del av svangerskapet. In Bergsjø P, Maltau JM, Molne K, Nesheim BI, Obstetrikk og Gynekologi. Gyldendal norske forlag. Second edition, first circulation, 2010.

21. Henriksen T, Molne K. Chapter 19. Avvikende fødsler, komplikasjoner og intervensjoner. In Bergsjø $\mathrm{P}$, Maltau JM, Molne K, Nesheim BI. Obstetrikk og Gynekologi. Gyldendal norske forlag. Second edition, first circulation, 2010. 